\title{
ARTICLE
}

Cite this: DOI: $10.1039 / \times 0 \times x 00000 x$

\section{Chiral tetranuclear and dinuclear copper(II) complexes for TEMPO-mediated aerobic oxidation of alcohols: are four metal centres better than two?}

Received 00th January 2012 Accepted 00th January 2012

DOI: $10.1039 / \times 0 \times x 00000 x$

www.rsc.org/

\author{
Guoqi Zhang, ${ }^{a}{ }^{*}$ Gloria Proni, ${ }^{a}$ Sherry Zhao, ${ }^{a}$ Edwin C. Constable, ${ }^{b}$ Catherine E. \\ Housecroft, ${ }^{,}$Markus Neuburger ${ }^{b}$ and Jennifer A. Zampese ${ }^{b}$
}

\begin{abstract}
The one-pot reaction of 3,5-di-tert-butyl-2-hydroxybenzaldehyde, $(R)$-2-aminoglycinol and $\mathrm{Cu}(\mathrm{OAc})_{2} \cdot 2 \mathrm{H}_{2} \mathrm{O}$ in a 1:1:1 ratio in the presence of triethylamine led to the isolation of X-ray quality crystals of the chiral complex $(R)-1$ in high yield. The single crystal structure of $(R)-1$ reveals a tetranuclear copper(II) complex that contains a $\left\{\mathrm{Cu}_{4}(\mu-\mathrm{O})_{2}\left(\mu_{3}-\mathrm{O}\right)_{2} \mathrm{~N}_{4} \mathrm{O}_{4}\right\}$ core. A reaction using (1S,2R)-2-amino-1,2-diphenylethanol as precursor under the same conditions generated the chiral complex $(S, R)$-2; its structure was determined by single crystal X-ray crystallography and was found to contain a $\left\{\mathrm{Cu}_{2}(\mu-O){ }_{2} \mathrm{~N}_{2} \mathrm{O}_{2}\right\}$ core. Both $(R)-\mathbf{1}$ and $(S, R)-2$ have been used for catalytic aerobic oxidation of benzylic alcohols in combination with the TEMPO (2,2,6,6-tetramethylpiperidinyl-1-oxyl) radical. (R)-1 selectively catalyses the conversion of various aromatic primary alcohols to the corresponding aldehydes with high yields (99\%) and TONs (up to 770$)$ in the air, while $(S, R)-2$ exhibits less promising catalytic performance under the same reaction conditions. The role of the cluster structures in $(R)-\mathbf{1}$ and $(S, R)-\mathbf{2}$ in controlling the reactivity towards aerobic oxidation reactions is discussed.
\end{abstract}

\section{Introduction}

The oxidation of alcohols to carbonyl compounds is an important transformation in synthetic organic chemistry and extensive efforts have been focused on the development of atom-economic oxidation methodologies for such reactions. ${ }^{1-4}$ Amongst the protocols developed to date, catalytic aerobic oxidation has proven to be especially efficient and valuable by virtue of the use of a low-loaded, low-cost catalyst and molecular oxygen from the air. ${ }^{5-10}$ In the past two decades, copper-catalysed, TEMPO (2,2,6,6-tetramethylpiperidinyl-1oxyl) mediated aerobic oxidation has been the most popular choice of catalyst systems since the pioneering work of Semmelhack and coworkers in 1984. These authors utilized a $\mathrm{CuCl} / \mathrm{TEMPO}$ system in DMF ( $N, N$-dimethylformamide) to furnish the aerobic oxidation of benzylic and allylic alcohols. ${ }^{11}$ Recent progress indicates that both $\mathrm{Cu}(\mathrm{I})$ and $\mathrm{Cu}(\mathrm{II})$ complexes with a $N, N$ - or $N, O$-ligands in combination with TEMPO could be efficient catalysts or catalyst precursors for the aerobic oxidation of various alcohols, and of particular note is a highly efficient copper/2,2'-bipyridine/TEMPO system developed by the Stahl group. ${ }^{12-17}$ However, the types of organic ligands exploited in the copper catalyst systems are still limited and the structures of copper catalysts involved in the catalytic process are rarely explored. ${ }^{17-20}$

The construction of metal-organic cluster compounds through self-assembly of predesigned ligands with appropriate metal ions is a prime research topic ${ }^{21-25}$ due to the advantages in catalysing useful chemical transformations, in contrast to simple monometallic complexes. ${ }^{26-30}$ Schiff base type ligands are excellent ligand candidates for high-nuclearity metallosupramolecular assemblies, in particular in cases where additional $O$-donor atoms have been introduced to the backbone of a Schiff base ligand scaffold. ${ }^{31-35}$ In search of active multimetallic copper catalysts for the aerobic oxidation reactions, we are particularly interested in exploring the catalytic performance of multinuclear copper(II) complexes based on simple Schiff base-type $N, O$-ligands. Although a dinuclear $\mathrm{Cu}^{\mathrm{II}}-\mathrm{N}, \mathrm{O}$ complex has been reported to catalyse the aerobic oxidation of primary alcohols and carbohydrates several years ago, suggesting the great potential of multimetallic copper complexes in catalytic alcohol oxidations, the structures of the catalyst species were not elucidated. ${ }^{36,37}$ Higher nuclearity copper(II) complexes are less studied in terms of the catalytic oxidation reactions. ${ }^{38,39}$ 
Herein, we report the one-pot syntheses and crystal structures of two tetranuclear and dinuclear copper(II) complexes resulting from the in situ synthesis of chiral Schiff base ligands (Scheme 1), and their catalytic applications in the TEMPO-mediated aerobic oxidation of benzylic alcohols. The catalytic potential of two complexes is compared based on their catalytic performance in various alcohol oxidation reactions, suggesting that the copper(II) complex with a $\mathrm{Cu}_{4}$ core is a more efficient catalyst than that one having a $\mathrm{Cu}_{2}$ core.

\section{Experimental Section}

\section{General}

Solvents were purchased from Sigma-Aldrich in the US. All reactions were performed under ambient conditions (no inert atmosphere). Optically pure $(R)$ - or $(S)$-2-aminoglycinol, (1S,2R)-2-amino-1,2-diphenylethanol, and 3,5-di-tert-butyl-2hydroxybenzaldehyde were purchased from Sigma-Aldrich in the US and were used as received. Solution electronic absorption spectra were recorded on an Agilent 8453 spectrophotometer, and FT-IR spectra using a Shimadzu $8400 \mathrm{~S}$ instrument with solid samples using a Golden Gate ATR accessory. Electrospray ionization (ESI) mass spectra were recorded using a Bruker esquire 3000plus mass spectrometer. Circular Dichroism (CD) spectra were measured in a $10-\mathrm{mm}$ quartz cell using a JASCO J-820 spectropolarimeter. GC-MS analysis was carried out on a Shimadzu GCMS-QP2010S gas chromatograph mass spectrometer.

\section{Preparation of $(R)-1$}

(R)-2-Aminoglycinol $(27.4 \mathrm{mg}, 0.200 \mathrm{mmol})$ and 3,5-di-tert-butyl-2hydroxybenzaldehyde $(46.8 \mathrm{mg}, 0.200 \mathrm{mmol})$ were dissolved in $\mathrm{CH}_{2} \mathrm{Cl}_{2} / \mathrm{CH}_{3} \mathrm{OH}\left(9.0 \mathrm{~cm}^{3}, \mathrm{v} / \mathrm{v}, 2: 1\right)$. Solid $\mathrm{Cu}(\mathrm{OAc})_{2} \cdot 2 \mathrm{H}_{2} \mathrm{O}(43.4 \mathrm{mg}$, $0.200 \mathrm{mmol}$ ) was then added under stirring at room temperature, followed by addition of triethylamine $(20.2 \mathrm{mg}, 0.200 \mathrm{mmol})$. The resulting deep-green solution was allowed to stir for $1 \mathrm{~h}$, then filtered. Slow evaporation of the filtrate over three days resulted in the formation of deep-green block-like crystals, which were suitable for single-crystal X-ray analysis. The bulk product of $(R)-\mathbf{1}$ was collected by filtration after one week, washed with $\mathrm{MeOH}$ and dried in vacuo. Yield: $74.0 \mathrm{mg}(89.4 \%)$. UV-Vis $\lambda_{\max } / \mathrm{nm}\left(1.0 \times 10^{-5} \mathrm{~mol}\right.$ $\left.\mathrm{dm}^{-3}, \mathrm{CH}_{2} \mathrm{Cl}_{2}\right) 234\left(\varepsilon / 10^{3} \mathrm{dm}^{3} \mathrm{~mol}^{-1} \mathrm{~cm}^{-1} 113\right), 281$ (80.1), 387 (29.7), 608 (0.942). FT-IR (solid, $\mathrm{cm}^{-1}$ ): 2951m, 2907w, 2863w, $1616 \mathrm{~s}, 1525 \mathrm{~m}, 1429 \mathrm{~s}, 1384 \mathrm{w}, 1361 \mathrm{w}, 1325 \mathrm{~m}, 1255 \mathrm{~m}, 1233 \mathrm{w}$, 1199w, 1164s, 1066w, 1029m, 942w, 911w, 842m, 699s, 668s. ESIMS $\left(\mathrm{CH}_{2} \mathrm{Cl}_{2} / \mathrm{MeOH}\right) \mathrm{m} / \mathrm{z} 1682.0[\mathrm{M}+\mathrm{Na}]^{+}$(calc. 1681.6), 1660.0 $[\mathrm{M}+\mathrm{H}]^{+}$(calc. 1660.6), $1267.7\left[\mathrm{Cu}_{3}(\mathrm{~L})_{3}+\mathrm{Na}\right]^{+}$(calc. 1267.4), $1245.9\left[\mathrm{Cu}_{3}(\mathrm{~L})_{3}+\mathrm{H}\right]^{+}$(base peak, calc. 1245.5), $851.7\left[\mathrm{Cu}_{2}(\mathrm{~L})_{2}+\right.$ $\mathrm{Na}]^{+}$(calc. 851.3), 829.3 $\left[\mathrm{Cu}_{2}(\mathrm{~L})_{2}+\mathrm{H}\right]^{+}$(calc. 829.7), 415.2 $[\mathrm{Cu}(\mathrm{L})$ $+\mathrm{H}]^{+}$(calc. 415.2), where L denotes the deprotonated Schiff base ligand. Found $\mathrm{C}$ 65.10, $\mathrm{H} \quad 7.03, \mathrm{~N} \quad 3.37 \%$; $\mathrm{C}_{92} \mathrm{H}_{116} \mathrm{Cu}_{4} \mathrm{~N}_{4} \mathrm{O}_{8} \cdot 0.5 \mathrm{CH}_{2} \mathrm{Cl}_{2}$ requires $\mathrm{C} 65.25, \mathrm{H} 6.93, \mathrm{~N} 3.29 \%$.

\section{Preparation of $(S)-1$}

The complex was prepared as for $(R)-1$ starting with $(S)$-2aminoglycinol (27.4 mg, $0.200 \mathrm{mmol}), 3,5$-di-tert-butyl-2hydroxybenzaldehyde (46.8 mg, $0.200 \mathrm{mmol}), \mathrm{Cu}(\mathrm{OAc})_{2} \cdot 2 \mathrm{H}_{2} \mathrm{O}$ $(43.4 \mathrm{mg}, 0.200 \mathrm{mmol})$ and triethylamine $(20.2 \mathrm{mg}, 0.200$ mmol). (S)-1 was isolated as black-green crystals $(71.6 \mathrm{mg}$, $86.5 \%$ ). Spectroscopic data (UV-Vis, IR and ESI-MS) matched those of $(R)-1$. Found $\mathrm{C}$ 65.13, $\mathrm{H}$ 6.84, N 3.49\%; $\mathrm{C}_{92} \mathrm{H}_{116} \mathrm{Cu}_{4} \mathrm{~N}_{4} \mathrm{O}_{8} \cdot 0.5 \mathrm{CH}_{2} \mathrm{Cl}_{2}$ requires C 65.25, H 6.93, N 3.29\%.

\section{Preparation of $(S, R)-2$}

The complex was prepared as for $(R)-\mathbf{1}$ starting with $(1 S, 2 R)-2-$ amino-1,2-diphenylethanol (42.6 mg, $0.200 \mathrm{mmol}), 3,5$-di-tertbutyl-2-hydroxybenzaldehyde $(46.8 \mathrm{mg}, \quad 0.200 \mathrm{mmol})$, $\mathrm{Cu}(\mathrm{OAc})_{2} \cdot 2 \mathrm{H}_{2} \mathrm{O}(43.4 \mathrm{mg}, 0.200 \mathrm{mmol})$ and triethylamine (20.2 $\mathrm{mg}, 0.200 \mathrm{mmol})$. X-ray quality deep-green block-like crystals of complex $(S, R)-2$ were harvested after a week; crystals were picked for single-crystal $\mathrm{X}$-ray analysis and catalytic reactions. Yield: $80.0 \mathrm{mg}(81.6 \%)$. UV-Vis $\lambda_{\max } / \mathrm{nm}$ $\left(2.0 \times 10^{-5} \mathrm{~mol} \mathrm{dm}{ }^{-3}, \mathrm{CH}_{2} \mathrm{Cl}_{2}\right) 243\left(\varepsilon / 10^{3} \mathrm{dm}^{3} \mathrm{~mol}^{-1} \mathrm{~cm}^{-1} 49.7\right)$, 282 (46.3), 292sh (31.8), 389 (13.8), 623 (0.500). FT-IR (solid, $\mathrm{cm}^{-1}$ ): $2951 \mathrm{~m}, 2870 \mathrm{w}, 1616 \mathrm{~s}, 1528 \mathrm{~m}, 1429 \mathrm{~s}, 1383 \mathrm{~m}, 1359 \mathrm{w}$, $1323 \mathrm{w}, 1255 \mathrm{~m}, 1232 \mathrm{w}, 1198 \mathrm{w}, 1167 \mathrm{~s}, 1038 \mathrm{w}, 1024 \mathrm{~m}, 840 \mathrm{~s}$, $786 \mathrm{~m}, 747 \mathrm{w}, 721 \mathrm{~s}, 700 \mathrm{~s}$. ESI-MS $\left(\mathrm{CH}_{2} \mathrm{Cl}_{2} / \mathrm{MeOH}\right) \mathrm{m} / \mathrm{z} 1495.9$ $\left[\mathrm{Cu}_{3}\left(\mathbf{L}^{\prime}\right)_{3}+\mathrm{Na}\right]^{+}$(calc. 1495.5), $1473.9\left[\mathrm{Cu}_{3}\left(\mathbf{L}^{\prime}\right)_{3}+\mathrm{Na}\right]^{+}$(calc. 1473.6), $1003.6[\mathrm{M}+\mathrm{Na}]^{+}$(calc. 1003.4), $981.8[\mathrm{M}+\mathrm{H}]^{+}$(base peak, calc. 981.4), $491.3\left[\mathrm{Cu}\left(\mathbf{L}^{\prime}\right)+\mathrm{H}\right]^{+}$(calc. 491.2), where $\mathbf{L}^{\prime}$ denotes the deprotonated Schiff base ligand. Found $\mathrm{C} 70.04, \mathrm{H}$ 7.10, $\mathrm{N} 2.99 \% ; \mathrm{C}_{58} \mathrm{H}_{66} \mathrm{Cu}_{2} \mathrm{~N}_{2} \mathrm{O}_{4} \cdot 0.2 \mathrm{CH}_{2} \mathrm{Cl}_{2}$ requires $\mathrm{C} 69.96, \mathrm{H}$ $6.70, \mathrm{~N} 2.80 \%$.

\section{General Procedure for Catalytic Aerobic Oxidation}

Under typical conditions, the reactions were performed in flasks fitted with water circulated condensors which are open to the air. $1.0 \mathrm{mmol}$ of substrate, $0.0025 \mathrm{mmol}$ of $(R)-\mathbf{1}(0.25$ mol\%) and $0.050 \mathrm{mmol}$ TEMPO (5 mol\%) were placed in the flask, to which $5 \mathrm{~cm}^{3}$ of $0.2 \mathrm{M}$ aqueous $\mathrm{K}_{2} \mathrm{CO}_{3}$ solution was sequentially added. The reaction was heated to $70{ }^{\circ} \mathrm{C}$ for $22 \mathrm{~h}$ under rigorous stirring, after which a solution of $\mathrm{HCl}\left(5 \mathrm{~cm}^{3}\right.$, $0.2 \mathrm{M}$ in $\mathrm{H}_{2} \mathrm{O}$ ) was added to neutralize the reaction mixture. Ethyl acetate $\left(5 \mathrm{~cm}^{3}\right)$ was then added to extract the organic components from the reaction mixture and $50 \mu \mathrm{L}$ of $1,2,4-$ trimethylbenzene was added to the organic phase as an internal standard. The products were diluted with dichloromethane and analyzed by GC-MS and yields obtained by using the internal standard method.

\section{Crystal Structure Determinations}

Data were collected on a Stoe IPDS or Bruker APEXII diffractometer; Stoe IPDS software ${ }^{40}$, SHELXL97 $7^{41}$ and CRYSTALS $^{42}$ were used for the data reduction, solution and refinement. ORTEP and molecular packing figures were drawn with the programme Mercury v. 2.4. ${ }^{43,44}$ CCDC 993832 and 993833 contain the supplementary crystallographic data for this paper. These data can be obtained free of charge via 
http://www.ccdc.cam.ac.uk/conts/retrieving.html (or from the Cambridge Crystallographic Data Centre, 12 Union Road, Cambridge CB2 1EZ, UK; fax: (+44) 1223-336-033; or e-mail: deposit@ccdc.cam.ac.uk).

(R)-1: $\mathrm{C}_{187} \mathrm{H}_{238} \mathrm{Cl}_{6} \mathrm{Cu}_{8} \mathrm{~N}_{8} \mathrm{O}_{16}, \quad M=3575.04$, green block, monoclinic, space group $C 2, a=22.255(2), b=17.369(2), c=$ 12.8760(13) $\AA, \beta=112.095(7)^{\mathrm{o}}, U=4611.7(9) \AA^{3}, Z=1, D_{c}=$ $1.287 \mathrm{Mg} \mathrm{m}^{-3}, \mu(\mathrm{Mo}-\mathrm{K} \alpha)=1.051 \mathrm{~mm}^{-1}, T=173(2) \mathrm{K}$. Total 91084 reflections, 11623 unique. Refinement of 11525 reflections (602 parameters) with $I>2 \sigma(I)$ converged at final $R_{1}$ $=0.0391\left(R_{1}\right.$ all data $\left.=0.0396\right), w R_{2}=0.1048\left(w R_{2}\right.$ all data $=$ $0.1051)$, GOF $=1.080$, Flack parameter $=0.030(9)$.

(S,R)-2: $\mathrm{C}_{58.70} \mathrm{H}_{67.40} \mathrm{Cl}_{1.40} \mathrm{Cu}_{2} \mathrm{~N}_{2} \mathrm{O}_{4}, M=1041.72$, green block, orthorhombic, space group $P 22_{1} 2, a=18.3910(14), b=$ 22.5070(17), $c=13.8020(10) \AA, U=5713.0(7) \AA^{3}, Z=4, D_{c}=$ $1.211 \mathrm{Mg} \mathrm{m}^{-3}, \mu(\mathrm{Mo}-\mathrm{K} \alpha)=0.854 \mathrm{~mm}^{-1}, T=123 \mathrm{~K}$. Total 13164 reflections, 11344 unique. Refinement of 10612 reflections (651 parameters) with $I>2 \sigma(I)$ converged at final $R_{1}$ $=0.0403\left(R_{1}\right.$ all data $\left.=0.0436\right), w R_{2}=0.0465\left(w R_{2}\right.$ all data $=$ $0.0483)$, GOF $=1.0844$, Flack parameter $=0.010(8)$.

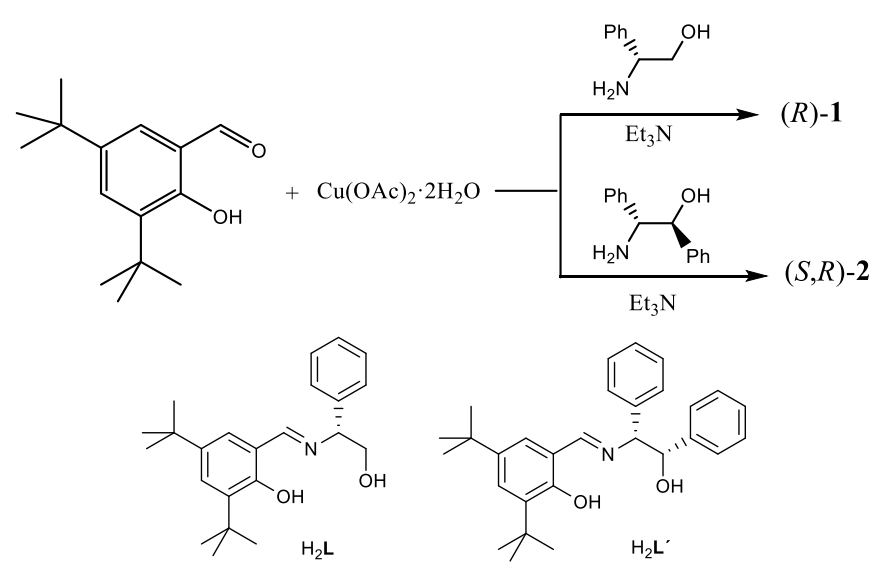

Scheme 1. One-pot syntheses of tetranuclear copper(II) complex $(R)-\mathbf{1}$ and dinuclear $(S, R)-\mathbf{2}$, and the structures of Schiff base ligands formed in situ.

\section{Results and Discussion}

\section{Synthesis and Structural Description}

Stirring a mixture of 3,5-di-tert-butyl-2-hydroxybenzaldehyde, (R)-2-aminoglycinol and $\mathrm{Cu}(\mathrm{OAc})_{2} \cdot 2 \mathrm{H}_{2} \mathrm{O}$ in a $1: 1: 1$ ratio in a mixture of $\mathrm{CH}_{2} \mathrm{Cl}_{2}$ and $\mathrm{MeOH}$ in the presence of 1.0 equiv. triethylamine led to a deep-green solution, from which green blocks formed after a week of slow evaporation of the solvent (Scheme 1). The X-ray quality crystals of $(R)$-1 (for simplicity, $(R)-1$ is used to represent complex $(R, R, R, R)$-1 with four $(R)$ ligands) were isolated in $89.4 \%$ yield and characterized by UVVis and IR spectroscopies, ESI-MS, elemental analysis and Xray crystallography. The IR spectrum revealed a strong absorption at $1616 \mathrm{~cm}^{-1}$, assigned to the imine bonds of the Schiff base ligand in $(R)-\mathbf{1}$, and the absorption at $605 \mathrm{~nm}$ in the $\mathrm{UV}-\mathrm{Vis}$ spectrum was consistent with the characteristic band of
copper(II) Schiff base complexes. ${ }^{45}$ The ESI mass spectrum recorded in a dilute $\mathrm{CH}_{2} \mathrm{Cl}_{2} / \mathrm{MeOH}$ solution exhibited peak envelopes at $m / z 1682.0$ and 1660.0 that were assigned to $[\mathrm{M}+$ $\mathrm{Na}]^{+}$and $[\mathrm{M}+\mathrm{H}]^{+}$, respectively, consistent with the presence of a tetranuclear tetra-ligand complex in solution. In addition, peak envelopes were also observed at $m / z$ 1267.7, 1245.9, 851.7, 829.3 and 415.2, suggesting the presence of tri-, di- and mono-nuclear $\mathrm{Cu}(\mathrm{II})$ species. All isotope patterns matched those simulated.

Single-crystal structural analysis of $(R)-\mathbf{1} \cdot 2 \mathrm{CH}_{2} \mathrm{Cl}_{2}$ unambiguously confirmed the formation of a tetranuclear complex (Fig. 1). (R)-1 $2 \mathrm{CH}_{2} \mathrm{Cl}_{2}$ crystallizes in the monoclinic space group $C 2$ with half of the tetranuclear cluster and a cocrystallized dichloromethane molecule in the asymmetric unit, and the second half is generated by a $\mathrm{C}_{2}$ axis. The absolute structure was determined by the Flack parameter that was

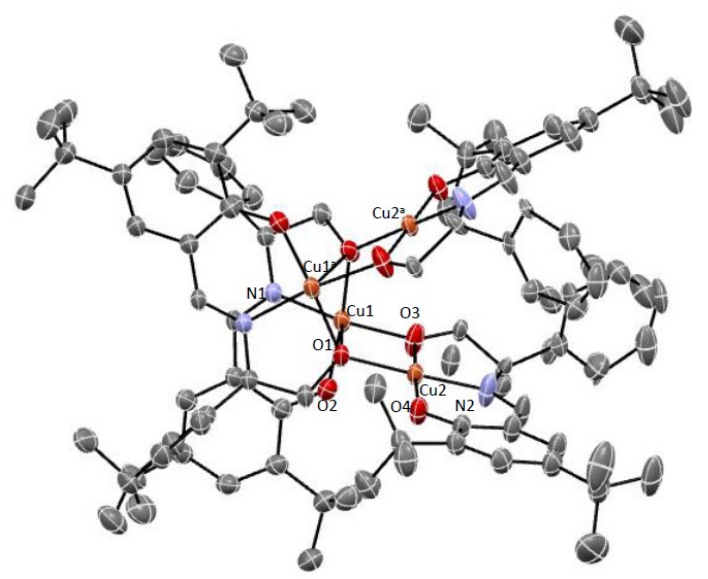

Fig. 1. X-ray structure of $(R)-1$ with ellipsoids plotted at the $50 \%$ probability level, and $\mathrm{H}$ atoms and dichloromethane solvent omitted for clarity. Selected bond lengths: $\mathrm{Cu} 1-\mathrm{O} 2=1.898(2), \mathrm{Cu}_{1}-\mathrm{O}^{\mathrm{a}}=1.936(2), \mathrm{Cu} 1-\mathrm{N} 1=1.937(2), \mathrm{Cu} 1-\mathrm{O} 1=$ $1.9613(19), \mathrm{Cu} 2-\mathrm{O} 4=1.869(2), \mathrm{Cu} 2-\mathrm{O} 3=1.903(2), \mathrm{Cu} 2-\mathrm{N} 2=1.919(2), \mathrm{Cu} 2-\mathrm{O} 1=$ $1.9362(18)$ Å. Symmetry code: $a=-\mathrm{x}, \mathrm{y},-\mathrm{z}$.

refined to $0.030(9)$. The complete molecular cluster without the solvated dichloromethane is depicted in Fig.1 and relevant bond lengths given in the caption are unexceptional. In each molecule, the four copper centres are surrounded by the bulky organic ligands resulting from the in-situ Schiff base condensation, and this forms a hydrophobic environment. However, significant unoccupied space in the coordination sphere is observed from both sides of the molecule along the crystallographic $a$ axis, as seen in a space-filling representation of the single molecule (Fig. 2). This provides accessible copper(II) sites that could be active for catalysis (vide infra). The tetranuclear cluster structure of $(R)-\mathbf{1}$ is best described in Fig. 3 as a $\left\{\mathrm{Cu}_{4}(\mu-\mathrm{O})_{2}\left(\mu_{3}-\mathrm{O}\right)_{2} \mathrm{~N}_{4} \mathrm{O}_{4}\right\}$ core. The bridging $\mu-\mathrm{O}$ atoms originate from the amino alcohol unit of the four ligands involved, while the imine- $N$ and phenoxy- $O$ atoms saturate the coordination spheres of all copper(II) centres. Two kinds of copper(II) centres $(\mathrm{Cu} 1, \mathrm{Cu} 2)$ with distinct coordination environments are observed: a square-planar $\mathrm{CuN}_{1} \mathrm{O}_{3}(\mathrm{Cu} 2)$ and a rectangular pyramidal $\mathrm{CuN}_{1} \mathrm{O}_{4}$ (Cu1). The $\mathrm{Cu}-\mathrm{O}_{\text {phenoxy }}$ distances are slightly shorter than those of $\mathrm{Cu}-\mathrm{O}_{\text {alcohol}}$, and the longest $\mathrm{Cu}-\mathrm{O}$ bond results from the axial coordination on $\mathrm{Cu} 1(\mathrm{Cu} 1-\mathrm{O} 1=1.9613(19))$. Taking the two 
symmetry-related $\mathrm{Cu}^{\mathrm{II}}$ centres into account, three $\mathrm{Cu}_{2} \mathrm{O}_{2}$ fourmember rings were found to be linked and folded to form a distorted open cubic geometry.

Crystals of $(S)-\mathbf{1}$ (for simplicity, $(S)$-1 is used to represent complex $(S, S, S, S)$-1 with four $(S)$-ligands) were also obtained by a similar procedure, using $(S)$-2-aminoglycinol as a starting material. All spectroscopic data (UV-Vis and IR spectroscopic and mass spectrometric) matched those of $(R)-\mathbf{1}$

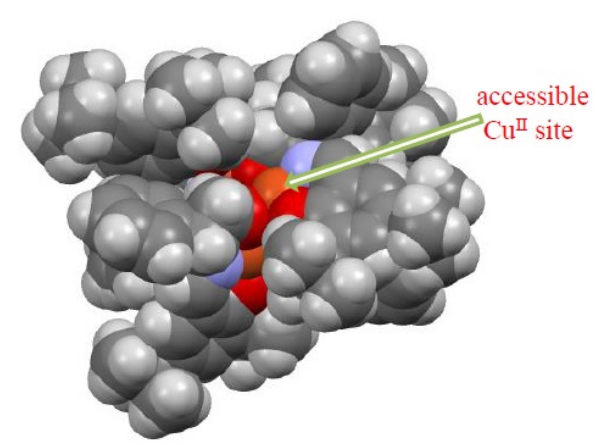

Fig. 2. The space-filling representation of a single molecule of $(R)-\mathbf{1}$ in $(R)$ $1 \cdot 2 \mathrm{CH}_{2} \mathrm{Cl}_{2}$, showing an accessible $\mathrm{Cu}^{\prime \prime}$ site. The solvent molecules are omitted for clarity.

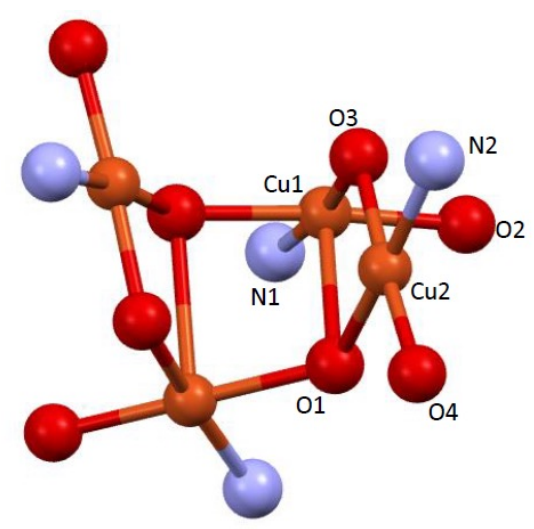

Fig. 3. The ball-stick representation of the $\mathrm{Cu}_{4} \mathrm{~N}_{4} \mathrm{O}_{8}$-core in $(R)-\mathbf{1} \cdot 2 \mathrm{CH}_{2} \mathrm{Cl}_{2}$. The labelling scheme is as in Fig. 1.

and elemental analysis revealed the same molecular composition as in $(R)$-1. The opposite chiralities of $(R)$ - and $(S)$-1 were confirmed by circular dichroism (CD) spectroscopy (Fig. 4). (R)-1 exhibits a positive Cotton effect, while $(S)-\mathbf{1}$ has a negative effect; both are mirror images, consistent with the two complexes being an enantiomeric pair, even though four stereogenic centres are involved in each $\mathrm{Cu}^{\mathrm{II}}$ complex.

In order to ascertain the influence of the steric hindrance of the ligand on the resulting cluster assembles, we next examined a similar one-pot self-assembly by using a more bulky chiral amino alcohol, (1S,2R)-2-amino-1,2diphenylethanol under the same condition (Scheme 1). Darkgreen X-ray quality crystals of $(S, R)-2 \quad((S, R)-2$ is used to signify the presence of two $(S, R)$-ligands in the complex) had grown after a week and were isolated in good yield. $(S, R)-2$ was also fully characterized by UV-Vis and IR spectroscopy, ESI-
MS, elemental analysis and single crystal X-ray crystallography. The IR spectrum showed an absorption at 1616 $\mathrm{cm}^{-1}$ assigned to the imine group. In the ESI-MS spectrum, the base peak envelope at $m / z 981.8$ was assigned to $[\mathrm{M}+\mathrm{H}]^{+}$, where $\mathrm{M}$ represents a neutral dinuclear bis-ligand complex.

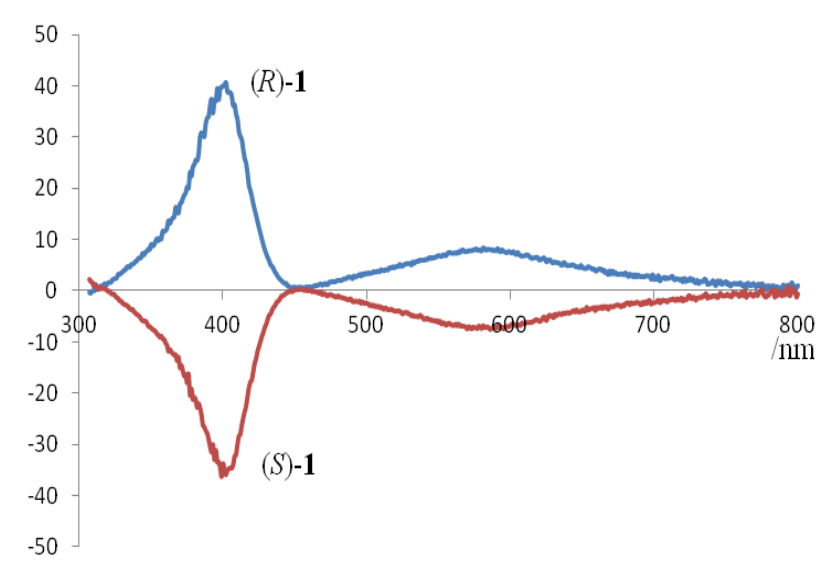

Fig. 4. The circular dichroism spectra of $(R)-1$ and $(S)-1$ in dichloromethane $(c=$ $\left.1.25 \times 10^{-4} \mathrm{M}\right)$.

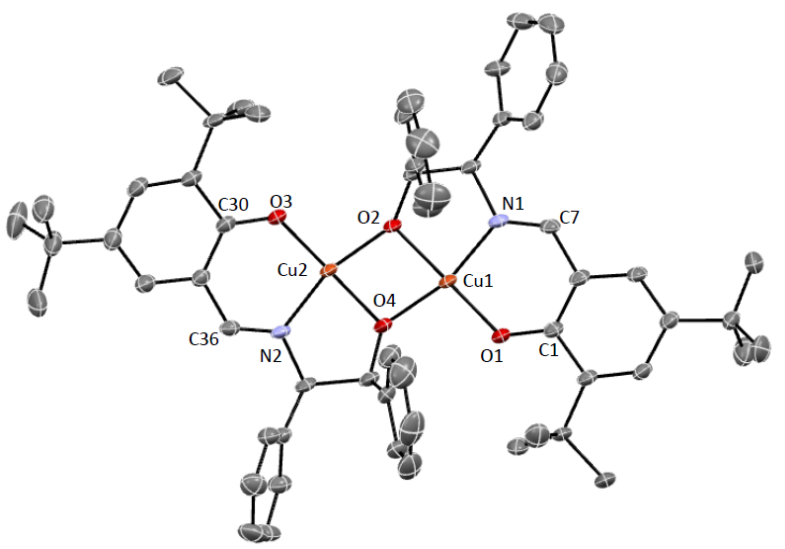

Fig. 5. Crystal structure of $(S, R)-2$ with ellipsoids plotted at the $50 \%$ probability level, and $\mathrm{H}$ atoms and dichloromethane solvent omitted for clarity. Selected bond parameters: $\mathrm{Cu} 1-\mathrm{N} 1=1.922(2), \mathrm{Cu} 1-\mathrm{O} 1=1.8603(16), \quad \mathrm{Cu} 1-\mathrm{O} 2=$ $1.9200(15)$, Cu1-O4 = 1.9310(17), Cu2-N2 = 1.931 (2), Cu2-O2 = 1.9451(17), Cu2$\mathrm{O} 3=1.8695(15), \mathrm{Cu} 2-\mathrm{O} 4=1.9223(15) \AA \AA$ N $1-\mathrm{Cu} 1-\mathrm{O} 1=95.80(8), \mathrm{N} 1-\mathrm{Cu} 1-\mathrm{O} 2=$ $84.86(7), \mathrm{O} 1-\mathrm{Cu} 1-\mathrm{O} 2=177.65(8), \mathrm{N} 1-\mathrm{Cu} 1-\mathrm{O} 4=164.09(7), \mathrm{O} 1-\mathrm{Cu} 1-\mathrm{O} 4=$ 100.07(7), O2-Cu1-O4 = 79.24(7), N2-Cu2-O2 = 162.49(7), N2-Cu2-O3 = 95.56(7), $\mathrm{O} 2-\mathrm{Cu} 2-\mathrm{O} 4=78.84(7)$, O3-Cu2-O4 = 176.96(8)․․

However, peak envelopes corresponding to a trinuclear trisligand complex were also observed, albeit in lower intensity. The CD spectrum of $(S, R)-2$ exhibits a positive Cotton effect and corresponds to its electronic absorption spectrum. The solid-state structure of this new copper complex was determined by X-ray crystallography. An ORTEP representation of $(S, R)-\mathbf{2}$ is depicted in Fig. 5 and relevant bond parameters are given in the caption. $(S, R)-\mathbf{2}$ crystallizes in the chiral orthorhombic space group $P 2{ }_{1} 2{ }_{1} 2$, containing a dinuclear $\mathrm{Cu}^{\mathrm{II}}$ complex and a co-crystallized dichloromethane molecule that is disordered in the asymmetric unit. In contrast to $(R)-\mathbf{1}$, 
the structure of $(S, R)-\mathbf{2}$ is composed of two tetra-coordinate, square planar $\mathrm{Cu}^{\text {II }}$ centres, bridged with two $\mu-\mathrm{O}$ atoms from

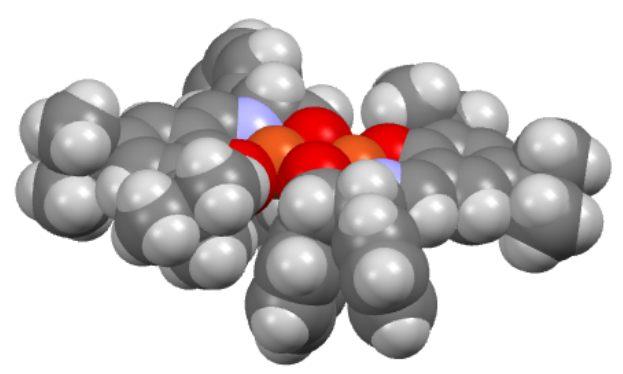

(a)

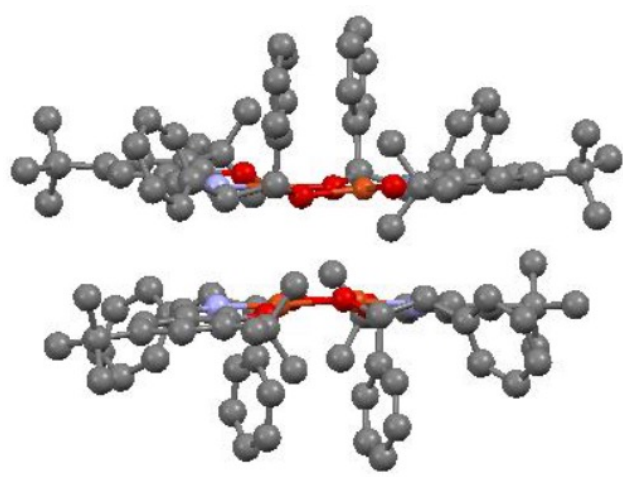

(b)

Fig. 6. (a)The space-filling representation of a single molecule in $(S, R)-\mathbf{2} \cdot \mathrm{CH}_{2} \mathrm{Cl}_{2}$. (b) the stick-ball structure showing two molecules stack face-to-face together with less hindered faces in the 3-D packing.

the amino alcohol unit of two ligands. Two metal centres have the same $\mathrm{N}_{1} \mathrm{O}_{3}$ coordination environment and the $\mathrm{Cu}-\mathrm{N}$ (1.922 and 1.931 $\AA$ ) and $\mathrm{Cu}-\mathrm{O}\left(1.86-1.93 \AA\right.$ ) bond lengths around two $\mathrm{Cu}^{\mathrm{II}}$ atoms are quite close, and also similar to those observed in $(R)-\mathbf{1}$. All $\mathrm{Cu}, \mathrm{N}$ and $\mathrm{O}$ atoms are distributed in an almost flat plane with the phenoxy units of two Schiff base ligands. Looking along the normal vector of the best plane through all atoms coordinated to the two metal centres it can be seen that the molecule displays almost perfect $\mathrm{C}_{2^{-}}$ symmetry, which however is not contained in the space group symmetry. As a consequence of this local symmetry, all four phenyl groups of the amino alcohols point to the same side of the plane of the $\mathrm{Cu}^{\mathrm{II}}$ cores, resulting in the metal centres on the other side being accessible, as is seen in Fig. 6a. However, further inspection of the 3-D packing shows that, in the solid state, pairs of molecules built up by the two-fold axes of the space group $P 2{ }_{1} 2{ }_{1} 2$ stack via a face-toface interaction together through the unblocked sides, with a relatively short intermolecular Cu...O contact of $3.34 \AA$ (Fig. 6b).

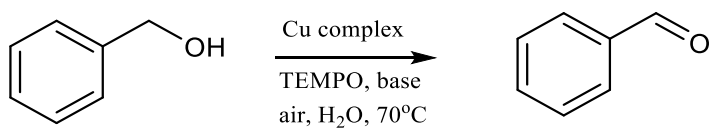

Scheme 2. Copper catalyzed, TEMPO-mediated aerobic oxidation of benzylic alcohol.

\section{Catalytic Studies}

The tetranuclear and dinuclear copper(II) complexes, $(R)-\mathbf{1}$ and $(S, R)$-2 were tested to catalyze the aerobic oxidation of benzylic alcohol to benzaldehyde, with base as an additive and in the presence of the TEMPO radical, as shown in Scheme 2. All reactions were performed on a $1.0 \mathrm{mmol}$ scale using copper(II) complexes as catalysts over a period of $22 \mathrm{~h}$ under conditions indicated in Table 1 . The yields of the carbonyl products were determined by GC-MS analysis while using 1,2,4trimethylbenzene as an internal standard, and the catalytic results are summarized in Table 1 . The fact that only aldehyde products were selectively formed and no corresponding carboxylic acid products detected is likely due to the known ability of TEMPO to scavenge free radicals, preventing the aldehydes from further auto-oxidation. ${ }^{18,46,47}$

It was recently reported that copper(II) complexes of a terpyridine derived ligand catalyzed the aerobic oxidation of benzylic alcohols in aqueous basic media with up to $94 \%$ yield. ${ }^{18,48}$ Initially, we performed the oxidation of benzylic alcohol by using copper complex $(R)-\mathbf{1}$ as catalyst with a low load $(0.25 \%)$ at room temperature and a $0.2 \mathrm{M}$ of $\mathrm{K}_{2} \mathrm{CO}_{3}$ solution in water as reaction media in the presence of TEMPO ( $5 \mathrm{~mol} \%$ ), by taking advantage of water as a green solvent. Pleasingly, $31 \%$ yield of the only product, benzaldehyde was detected after $22 \mathrm{~h}$ (entry 1, Table 1). In contrast, when the same reaction was performed in an acetonitrile solution only negligible product was observed (entry 2, Table 1). Elevating the reaction temperature to $70{ }^{\circ} \mathrm{C}$ resulted in the quantitative conversion of benzylic alcohol into benzaldehyde in aqueous $\mathrm{K}_{2} \mathrm{CO}_{3}$ solution (99\% GC yield, entry 3, Table 1) with a turnover number (TON) of 396. Reducing catalyst loading (substrate/catalyst ratio up to 1000/1) led to slightly lower yields, but the TON was improved to 770 (entries 4, 5, Table 1 ), which is well comparable to the highest TON value reported for this reaction. ${ }^{48}$ The use of TEMPO radical was crucial for this reaction, as almost no reaction was revealed when it was run without the presence of TEMPO (entry 6, Table 1). The role of base additive was also tested. When the reaction was carried out in the presence of triethylamine $\left(0.2 \mathrm{M}\right.$ in $\left.\mathrm{H}_{2} \mathrm{O}\right)$, instead of $\mathrm{K}_{2} \mathrm{CO}_{3}, 38 \%$ yield of benzaldehyde was obtained, while only trace amount of the product was found with the same base additive in acetonitrile (entries 8 and 9, Table 1). Other bases such as sodium hydroxide or potassium tertbutoxide were also inferior base additives for this reaction (entries 10 and 11, Table 1). Without the use of the copper complex as catalysts, the reaction performed under the same conditions but with copper(II) acetate ( 1 mol\% loading) resulted in only $12 \%$ yield of benzaldehyde (entry 24 , Table 1 ), indicating the essential role of $\mathrm{N}, \mathrm{O}$-coordinated copper(II) centres in catalysing the reactions. 


\section{ARTICLE}

\begin{tabular}{|c|c|c|c|c|c|c|c|}
\hline Entry & Complex & $\begin{array}{l}\text { Substrate } \\
\text { /complex }\end{array}$ & Substrate & Base & Product & Yield [\%] $^{\mathrm{b}}$ & TON \\
\hline $1^{\mathrm{c}}$ & $(R)-1$ & $400 / 1$ & benzyl alcohol & $\mathrm{K}_{2} \mathrm{CO}_{3}$ & benzaldehyde & 31 & 124 \\
\hline $2^{\mathrm{d}}$ & $(R)-1$ & $400 / 1$ & benzyl alcohol & $\mathrm{K}_{2} \mathrm{CO}_{3}$ & benzaldehyde & 1 & 4 \\
\hline 3 & $(R)-1$ & $400 / 1$ & benzyl alcohol & $\mathrm{K}_{2} \mathrm{CO}_{3}$ & benzaldehyde & 99 & 396 \\
\hline 4 & $(R)-\mathbf{1}$ & $500 / 1$ & benzyl alcohol & $\mathrm{K}_{2} \mathrm{CO}_{3}$ & benzaldehyde & 95 & 475 \\
\hline 5 & $(R)-1$ & $1000 / 1$ & benzyl alcohol & $\mathrm{K}_{2} \mathrm{CO}_{3}$ & benzaldehyde & 77 & 770 \\
\hline $6^{\mathrm{e}}$ & $(R)-\mathbf{1}$ & $400 / 1$ & benzyl alcohol & $\mathrm{K}_{2} \mathrm{CO}_{3}$ & benzaldehyde & 1 & 4 \\
\hline 7 & $(R)-1$ & $400 / 1$ & benzyl alcohol & no & benzaldehyde & 4 & 16 \\
\hline $8^{\mathrm{f}}$ & $(R)-1$ & $400 / 1$ & benzyl alcohol & $\mathrm{Et}_{3} \mathrm{~N}$ & benzaldehyde & 38 & 152 \\
\hline $9^{\mathrm{d}, \mathrm{f}}$ & $(R)-1$ & $400 / 1$ & benzyl alcohol & $\mathrm{Et}_{3} \mathrm{~N}$ & benzaldehyde & 1 & 4 \\
\hline $10^{\mathrm{f}}$ & $(R)-1$ & $400 / 1$ & benzyl alcohol & $\mathrm{NaOH}$ & benzaldehyde & 63 & 252 \\
\hline $11^{\mathrm{f}}$ & $(R)-1$ & $400 / 1$ & benzyl alcohol & $\mathrm{KO}^{t} \mathrm{Bu}$ & benzaldehyde & 9 & 36 \\
\hline 12 & $(R)-1$ & $400 / 1$ & 4-methylbenzyl alcohol & $\mathrm{K}_{2} \mathrm{CO}_{3}$ & 4-methylbenzaldehyde & 99 & 396 \\
\hline 13 & $(R)-1$ & $400 / 1$ & 4-bromobenzyl alcohol & $\mathrm{K}_{2} \mathrm{CO}_{3}$ & 4-bromobenzaldehyde & 99 & 396 \\
\hline 14 & $(R)-1$ & $400 / 1$ & 4-iodobenzyl alcohol & $\mathrm{K}_{2} \mathrm{CO}_{3}$ & 4-iodobenzaldehyde & 99 & 396 \\
\hline 15 & $(R)-1$ & $400 / 1$ & 4-nitrobenzyl alcohol & $\mathrm{K}_{2} \mathrm{CO}_{3}$ & 4-nitrobenzaldehyde & 68 & 272 \\
\hline 16 & $(R)-1$ & $400 / 1$ & 4-methoxybenzyl alcohol & $\mathrm{K}_{2} \mathrm{CO}_{3}$ & 4-methoxybenzaldehyde & 65 & 260 \\
\hline 17 & $(R)-1$ & $400 / 1$ & 1-octanol & $\mathrm{K}_{2} \mathrm{CO}_{3}$ & 1-octanal & 0 & 0 \\
\hline 18 & $(R)-1$ & $400 / 1$ & 1-phenylethanol & $\mathrm{K}_{2} \mathrm{CO}_{3}$ & acetophenone & 3 & 12 \\
\hline 19 & $(S, R)-\mathbf{2}$ & $200 / 1$ & benzyl alcohol & $\mathrm{K}_{2} \mathrm{CO}_{3}$ & benzaldehyde & 78 & 156 \\
\hline 20 & $(S, R)-\mathbf{2}$ & $200 / 1$ & 4-methylbenzyl alcohol & $\mathrm{K}_{2} \mathrm{CO}_{3}$ & 4-methylbenzaldehyde & 95 & 190 \\
\hline 21 & $(S, R)-\mathbf{2}$ & $200 / 1$ & 4-bromobenzyl alcohol & $\mathrm{K}_{2} \mathrm{CO}_{3}$ & 4-bromobenzaldehyde & 98 & 196 \\
\hline 22 & $(S, R)-\mathbf{2}$ & $200 / 1$ & 4-nitrobenzyl alcohol & $\mathrm{K}_{2} \mathrm{CO}_{3}$ & 4-nitrobenzaldehyde & 14 & 28 \\
\hline 23 & $(S, R)-\mathbf{2}$ & $200 / 1$ & 1-phenylethanol & $\mathrm{K}_{2} \mathrm{CO}_{3}$ & acetophenone & 2 & 4 \\
\hline 24 & $\mathrm{Cu}(\mathrm{OAc})_{2}$ & $100 / 1$ & benzyl alcohol & $\mathrm{K}_{2} \mathrm{CO}_{3}$ & benzaldehyde & 12 & 12 \\
\hline
\end{tabular}

${ }^{a}$ Condition: $1 \mathrm{mmol}$ of the substrate, $0.0025 \mathrm{mmol}(0.25 \mathrm{~mol} \%)$ of catalyst precursor and $0.05 \mathrm{mmol}(5 \mathrm{~mol} \%)$ of TEMPO in $5 \mathrm{~mL}$ of $0.2 \mathrm{M}^{2}$ aqueous K ${ }_{2} \mathrm{CO}_{3}$ solution, 1 atm. air, $70{ }^{\circ} \mathrm{C}, 22 \mathrm{~h} .{ }^{b}$ Yields based on GC-MS analysis, selectivity $>99 \%$ in all cases. ${ }^{\mathrm{c}}$ Reaction run at room temperature. ${ }^{\mathrm{d}}$ Reaction run in $\mathrm{CH}_{3} \mathrm{CN}$. ${ }^{\mathrm{e}}$ Reaction run without TEMPO. ${ }^{\mathrm{f}} 1 \mathrm{mmol}$ of base added;

Encouraged by the result described above, we next tested the oxidation of several substituted benzylic alcohols under the optimized conditions. Aromatic primary alcohols with both electron- withdrawing and donating groups can be converted to the corresponding aldehydes with moderate to high yields (up to $99 \%$ ) and high TONs, while the result was relatively worse while using 4-nitrobenzyl alcohol and 4-methoxybenzaldehyde as substrates (entries 12-16, Table 1). However, aliphatic or secondary benzylic alcohols were confirmed to be challenging substrates for oxidation under the optimized conditions (entries 17 and 18 ), as also found for other $\mathrm{Cu}^{\mathrm{II}} /$ TEMPO catalysts. ${ }^{18,48}$
The complex $(S, R)-2$ was also examined for the oxidation of benzylic alcohols. It was noted that the oxidation of benzyl alcohol resulted in a $78 \%$ yield of benzaldehyde, in the presence of $0.5 \mathrm{~mol} \%$ of $(S, R)-2$ under the same conditions (5 mol\% TEMPO, $5 \mathrm{~cm}^{3}$ of $0.2 \mathrm{M} \mathrm{K}_{2} \mathrm{CO}_{3}$ in water, $70{ }^{\circ} \mathrm{C}$ and 22 h), and the TON was much lower than that found for $(R)-\mathbf{1}(156$ vs. 770) (entry 19, Table 1). This indicated that complex $(S, R)$ $\mathbf{2}$ is a slightly poorer oxidation catalyst than $(R)-\mathbf{1}$. $(S, R)-\mathbf{2}$ also catalyzed the conversion of other substituted aromatic primary alcohols to the corresponding aldehydes in moderate to high yields, albeit with lower TONs (entries 20-22, Table 1). Again, 
the oxidation of 1-phenylethanol practically did not proceed with catalyst $(S, R)-\mathbf{2}$.

The different catalytic activities found for the two copper(II) complexes are probably due to their differing structures. As we described above, in the solid state, $(R)-1$ adopts a tetranuclear copper(II) cluster structure with a $\mu-\mathrm{O}$ bridged $\mathrm{Cu}_{4} \mathrm{~N}_{4} \mathrm{O}_{8}$ core, while $(S, R)-2$ contains a dinuclear $\mathrm{Cu}_{2} \mathrm{~N}_{2} \mathrm{O}_{4}$ unit surrounded by hydrophobic organic moieties. It is known that in a molecular catalyst containing more than one metal centre the Lewis acidity of a metal centre can be significantly enhanced by other closely linked Lewis acid sites through a Lewis acid-assisted Lewis acidity enhancement effect. ${ }^{26-28}$ We therefore assume that the substrate accessible $\mathrm{Cu}^{\mathrm{II}}$ site in $(R)-\mathbf{1}$ as shown in Fig. 2 is more acidic than any one of reactive $\mathrm{Cu}^{\mathrm{II}}$ centres in $(S, R)-\mathbf{2}$, and therefore better able to coordinate to the substrate benzylic alcohols (upon deprotonation) and TEMPO radical, which was believed to play an important role in initiating the catalytic cycle. ${ }^{18}$ Remarkably, it was also revealed that a trinuclear $\mathrm{Pd}_{3} \mathrm{O}_{2}$ cluster is an active intermediate for $\mathrm{Pd}^{\mathrm{II}}$-catalysed aerobic oxidation very recently. ${ }^{49}$ However, it is still unclear whether or not other factors such as intermolecular interactions also influence the catalytic activities of the copper(II) complexes. As described above, the catalytic reactions were carried out in an aqueous media, although both $\mathrm{Cu}^{\text {II }}$ complexes contain bulky hydrophobic organic periphery and are unlikely soluble in the solution, some open $\mathrm{Cu}^{\mathrm{II}}$ sites in the molecules of $(R)-1$ are still accessible for coordination by organic nucleophilic substrates (deprotonated benzylic alcohols) and TEMPO radicals and would catalyse the reaction. In $(S, R)-\mathbf{2}$, the possible intermolecular interactions between a pair of dinuclear molecules as found in the solid state (Fig. 6b) will probably prevent, the substrates and TEMPO from accessing to the $\mathrm{Cu}^{\mathrm{II}}$ sites, thus partially suppress the catalytic ability of $(S, R)$-2, although the polar substrates and TEMPO molecules might still interact with the active copper(II) centres in the reaction mixture under an aqueous environment. Therefore, this possibility cannot be excluded for explaining their reactivity difference. Further catalytic studies on related $\mathrm{Cu}^{\text {II }}$ cluster compounds would be highly desirable in order to uncover the structure-catalytic activity relationship between the metal catalysts with various nuclearities.

\section{Conclusions}

In conclusion, we have synthesized two chiral copper(II)-based Schiff base complexes, $(R)-\mathbf{1}$ and $(S, R)-\mathbf{2}$, respectively, through one-pot self-assembly reactions. Upon reacting the optically pure $\quad(R)$-2-aminoglycinol, 3,5-di-tert-butyl-2hydroxybenzaldehyde with copper(II) acetate in the presence of triethylamine, complex $(R)-\mathbf{1}$ has been isolated as single crystals. The crystal structure confirms that $(R)-\mathbf{1}$ is a chiral tetranuclear tetra-ligand complex containing a $\mathrm{Cu}_{4}(\mu-\mathrm{O})_{2}\left(\mu_{3^{-}}\right.$ $\mathrm{O})_{2} \mathrm{~N}_{4} \mathrm{O}_{4}$ core that is surrounded by the Schiff base ligands formed in situ. In contrast, $(S)-\mathbf{1}$ was also prepared by the same procedure using an $S$-configuration amino alcohol starting material and the CD spectra revealed the opposite chirality of the resulting copper(II) complexes. $(S, R)-2$ was subsequently synthesized by using a more bulky amino alcohol, $(1 S, 2 R)-2$ amino-1,2-diphenylethanol under the same reaction conditions, and the structural analysis shows $(S, R)-2$ is a dinuclear bisligand complex with two $\mu-\mathrm{O}$ bridging $\mathrm{Cu}^{\text {II }}$ centres. Both complexes have been applied to the catalytic aerobic oxidation of benzylic alcohols mediated by TEMPO. The results indicated that $(R)-1$ efficiently catalyzed the oxidation of benzyl alcohol in the air and in an aqueous $\mathrm{K}_{2} \mathrm{CO}_{3}$ solution with TON up to 770 , while relatively inferior results were observed when using $(S, R)-2$ as a catalyst under the same conditions. Other substrates were also tested in order to compare their different catalytic abilities. Although it was insufficient to draw a conclusion on what made the different reactivity of both $\mathrm{Cu}^{\text {II }}$ complexes for catalysis, based on the present data obtained in this research, we have tentatively attributed this to the factors of molecular structures (tetranuclear vs. dinuclear) and intermolecular interactions. Our further investigation will be focused on elucidating the structure-catalytic activity relationship and the catalytic mechanism involving multiple metal centres.

\section{Acknowledgements}

We thank the Office for the Advancement of Research at CUNY John Jay College for a Seed grant, and the Novartis Foundation, formerly Ciba-Geigy Jubilee Foundation for support.

\section{Notes and references}

${ }^{a}$ Department of Sciences, John Jay College, The City University of New York, New York, NY 10019, USA.

${ }^{b}$ Department of Chemistry, University of Basel, Spitalstrasse 51, CH 4056 Basel, Switzerland.

"Corresponding author. Email address: guzhang@jjay.cuny.edu

1 I.W.C.A. Arends and R.A. Sheldon, Modern Oxidation Methods (Ed.: J.-E. Bäckvall), Wiley, Weinheim, 2004, p.83.

2 P.J. Figiel, A. Sibaouih, J. U. Ahmad, M. Nieger, M.T. Räisänen, M. Leskelä and T. Repo, Adv. Synth. Catal. 2009, 351, 2625.

3 R.A. Sheldon and I.W.C.E. Arends, Adv. Synth. Catal., 2004,346,1051.

4 R.A. Sheldon, I.W.C.E. Arends, G-J.T. Brink and A. Dijksman, Acc. Chem. Res. 2002, 35, 774.

5 B.-Z. Zhan and A. Thompson, Tetrahedron 2004, 60, 2917.

6 T. Mallat and A. Baiker, Chem. Rev. 2004, 104, 3037.

7 I. E. Markó, P. R. Giles, M. Tsukazaki, I. Chellé-Regnaut, A. Gautier, R. Dumeunier, F. Philippart, K. Doda, J.-L. Mutonkole, S.M. Brown and C.J. Urch, Adv. Inorg. Chem. 2004, 56, 211.

8 M.S. Sigman and D.R. Jensen, Acc. Chem. Res. 2006, 39, 221.

9 T. Matsumoto, M. Ueno, N. Wang and S. Kobayashi, Chem.-Asian. J. 2008, 3, 196.

10 C. Parmeggiani and F. Cardona, Green Chem. 2012, 14, 547.

11 M.F. Semmelhack, C.R. Schmid, D.A. Cortes and C.S. Chou, J. Am. Chem. Soc. 1984, 106, 3374. 
12 B.A. Steinhoff, I.A. Guzei and S.S. Stahl, J. Am. Chem. Soc. 2004, 126, 11268.

13 B.A. Steinhoff and S. S. Stahl, J. Am. Chem. Soc. 2006, 128, 4348.

14 X. Ye, M.D. Johnson, T. Diao, M.H. Yates and S.S. Stahl, Green Chem. 2010, 12, 1180.

15 J.M. Hoover and S.S. Stahl, J. Am. Chem. Soc. 2011, 133, 16901.

16 J.M. Hoover, J.E. Steves and S.S. Stahl, Nat. Protoc. 2012, 7, 1161.

17 J.M. Hoover, B.L. Ryland and S.S. Stahl, ACS Catal. 2013, 3, 2599.

18 Z. Ma, L. Wei, E.C.B.A. Alegria, L.M.D.R.S. Martins, M.F.C.G. da Silva and A.J.L. Pombeiro, Dalton Trans. 2014, DOI: 10.1039/C3DT53054J.

19 M.N. Kopylovich, K.T. Mahmudov, M. Haukka, P.J. Figiel, A. Mizar, J.A.L. da Silva and A.J.L. Pombeiro, Eur. J. Inorg. Chem. 2011, 4175.

20 I. Gamba, I. Mukikainen, E. Bouwman, J. Reedijk and S. Bonnet, Eur. J. Inorg. Chem. 2013, 115 .

21 P.D. Frischmann, G.A. Facey, P.Y. Ghi, A.J. Gallant, D.L. Bryce, F. Lelj and M.J. MacLachlan, J. Am. Chem. Soc. 2010, 132, 3893.

22 H.L.C. Feltham and S. Brooker, Coord. Chem. Rev. 2009, 253, 1458.

23 G. Aromí, P. Gamez, O. Roubeau, H. Kooijman, A.L. Spek, W.L. Driessen and J. Reedijk, Angew. Chem., Int. Ed. 2002, 41, 1168.

24 A.W. Kleij, Chem.-Eur. J. 2008, 14, 10520.

25 J. Schemberg, K. Schneider, U. Demmer, E. Warkentin, A. Müller and U. Ermler, Angew. Chem., Int. Ed. 2007, 46, 2408.

26 M. Shibasaki and Y. Yamamoto, Multimetallic Catalysis in Organic Synthesis, Wiley-VCH, Weinheim, 2004.

27 N.E. Shepherd, H. Tanabe, Y. Xu, S. Matsunaga and M. Shibasaki, J. Am. Chem. Soc. 2010, 132, 3666.

28 I. Fujimori, T. Mita, K. Maki, M. Shiro, A. Sato, S. Furusho, M. Kanai and M. Shibasaki, J. Am. Chem. Soc. 2006, 128, 16438.

29 E.C. Constable, G. Zhang, C.E. Housecroft, M. Neuburger, S. Schaffner and W.-D. Woggon, New J. Chem. 2009, 33, 1064.

30 E.C. Constable, G. Zhang, C.E. Housecroft, M. Neuburger, S. Schaffner, W.-D. Woggon and J.A. Zampese, New J. Chem. 2009, 33, 2166.

31 S. Akine, T. Taniguchi and T. Nabeshima, Inorg. Chem. 2004, 43, 6142.

32 S. Akine, W. Dong and T. Nabeshima, Inorg. Chem. 2006, 45, 4677.

33 L. San Felices, E.C. Escudero-Adán, J. Benet-Buchholz and A.W. Kleij, Inorg. Chem. 2009, 48, 846.

34 S. Akine and T. Nabeshima, Dalton Trans. 2009, 10395.

35 P.D. Frischmann, A.J. Gallant, J.H. Chong and M.J. MacLachlan, Inorg. Chem. 2008, 47, 101.

36 S. Striegler, Tetrahedron, 2006, 62, 9109.

37 S. Striegler, N.A. Dunaway, M.G. Gichinga and L.K. Milton, Tetrahedron, 2010, 66, 7927.

38 P.J. Figiel, A.M. Kirillov, M.F.C. Guedes da Silva, J. Lasri and A.J.L. Pombeiro, Dalton Trans. 2010, 39, 9879.

39 P.J. Figiel, A.M. Kirillov, Y.Y. Karabach, M.N. Kopylovich and A.J.L. Pombeiro, J. Mol. Catal. A 2009, 305, 178.

40 Stoe \& Cie, IPDS software v 1.26, Stoe \& Cie, Darmstadt, Germany, 1996.

41 G.M. Sheldrick, Acta Crystallogr., Sect. A 2008, 64, 112.

42 P.W. Betteridge, J.R. Carruthers, R.I. Cooper, K. Prout and D.J. Watkin, J. Appl. Cryst. 2003, 36, 1487.

43 I.J. Bruno, J.C. Cole, P.R. Edgington, M.K. Kessler, C.F. Macrae, P.
McCabe, J. Pearson and R. Taylor, Acta Crystallogr., Sect. B 2002, 58, 389.

44 C.F. Macrae, I.J. Bruno, J.A. Chisholm, P.R. Edgington, P. McCabe, E. Pidcock, L. Rodriguez-Monge, R. Taylor, J. van de Streek and P.A. Wood, J. Appl. Cryst. 2008, 41, 466.

45 E.C. Constable, G. Zhang, C.E. Housecroft, M. Neuburger and S. Schaffner, CrystEngComm 2009, 11, 657.

46 A. Dijksman, A.M. González, A.M. Payeras, I. Arends and R.A. Sheldon, J. Am. Chem. Soc. 2001, 123, 6826.

47 R.A. Sheldon and I.W.C.E. Arends, Adv. Synth. Catal. 2004, 346, 1051.

48 A. Soroceanu, M. Cazacu, S. Shova, C. Turta, J. Kožíšek, M. Gall, M. Breza, P. Rapta, T.C.O. MacLeod, A.J.L. Pombeiro, J. Telser, A.A. Dobrov and V.B. Arion, Eur. J. Inorg. Chem. 2013, 1458.

49 A.J. Ingram, D. Solis-Ibarra, R.N. Zare and R.M. Waymouth, Angew. Chem., Int. Ed. 2014, DOI: 10.100./anie.201400134. 